\title{
A reply to comments on "Figural aftereffects, illusions and the dimension of field dependence"
}

\section{ALEXANDER W. PRESSEY, DEPARTMENT OF PSYCHOLOGY, UNIVERSITY OF MANITOBA, Winnipeg, Canada}

In commenting on a study by Pressey \& Koffman (1968) in which a relationship between visual figural aftereffects (FAEs) and field dependence was not found, Immergluck (1968) offers several possibilities for the failure to find such a relationship. He states that our study was "in no ways a direct replication" of his experiment and differences in method, stimuli, and instructions could perhaps account for the results. It may be stated, however, that a "direct" replication was not intended. The intention was, in part, to determine "to what degree the relationship (found by Immergluck) is representative of results that would obtain when different measures of field dependence and FAEs are used."

Originally it was intended to use a design that was more similar to the design employed by Immergluck. For example, selection of $\mathrm{Ss}$ on the basis of a measure of field dependence (RFT) rather than susceptibility to FAEs was considered but was rejected because very few Ss qualified under Immergluck's criterion for field dependence. Immergluck stated that his field dependent group consisted of Ss who showed a "consistent deviation of $10 \mathrm{deg}$ or more." On the hasis of available data (Pressey, 1967) it
PER

OF

CASES

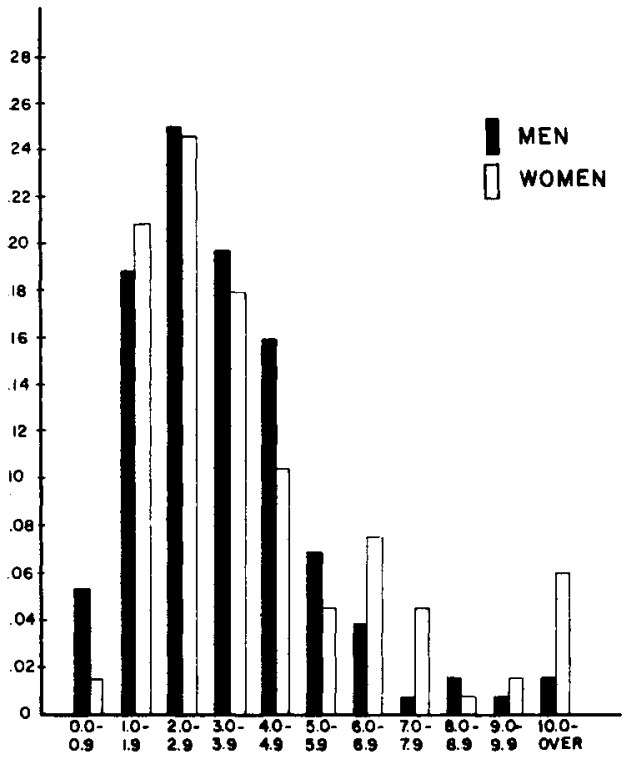

SCORES ON ROD-AND-FRAME TEST
Fig. 1 Frequency distributions of scores on the Rod-and-Frame Test. was found that only two Ss (both women) out of 60 Ss showed a consistent deviation of $10 \mathrm{deg}$ or more. Since that time more data has become available from five different experiments (including the study by Pressey \& Koffman, 1968) in which the RF' was utilized. The same apparatus was used in all studies and the method of testing was very similar. At least four trials were given to a $S$ who was seated $12 \mathrm{ft}$ in front of the target. The room was completely darkened, and the frame was tilted 26 deg either to S's left or right. The rod was also tilted $26 \mathrm{deg}$ either to S's left or right so that all combinations of frame left, rod left; frame right, rod left; frame left, rod right; and frame right, rod right were given. The order of presenting the four combinations, however, varied among experiments. The Ss score was the average deviation (discounting direction of deviation) from the vertical on the first four trials. A frequency distribution of scores for 134 women and 132 men is shown in Fig. 1. The data shows that only eight women and two men exhibited a consistent deviation of $10 \mathrm{deg}$ or more. Thus, a prohibitive amount of testing would have been required to obtain even a small group of male field dependent Ss.

Immergluck also states that the findings of Pressey \& Koffman (1968) "contradict not only our results but, perhaps more seriously, they stand in contradiction to a long line of established literature ... in that they also fail to show any sex differences in their own measures of field dependence." One wonders how Immergluck reconciles this statement with his claim that his "S groups, both field dependent and field independent, contain in all our investigations about an equal number of both sexes." This claim too "stands in contradiction to a long line of established literature" and it also is contradicted by the data shown in Fig. 1. Despite the fact that in the study reported by Pressey \& Koffman (1968) a sex difference was not found, the overall results from several studies show that there are more women exhibiting large errors on the RFT than men.

However, it may still be argued that in the study of Pressey \& Koffman (1968) the sample of Ss was not a representative one and that the failure to find a relationship between field dependence and susceptibility to FAEs was due to a sampling error. A defense against such an argument cannot be made since it is not possible to prove the non-existence of a particular state-of-affairs. In such a case, however, it is suggested that the burden of proof lies on the side that claims that a relationship between field dependence and FAEs exists. And until evidence is obtained under conditions in which the sex of $S$ cannot confound the results, the claim that field dependence and susceptibility to FAEs are related must be viewed with some skepticism.

\section{REFERENCES}

IMMERGLUCK, L. Comment on "Figural aftereffects, illusions and the dimension of field dependence." Psychon. Sci., 1968, 11, 363.

PRESSEY, A. W. Field dependence and susceptibility to the Poggendorff illusion. Percept. mot. Skills, 1967, 24, 309-310.

PRESSEY, A. W., \& KOFFMAN, G. Figural aftereffects, illusions and the dimension of field dependence. Psychon. Sci, 1968, 10, 279-280. 